\title{
Concrete Subjected to Varying Confinement, I: Experimental Evaluation
}

\author{
Fatih Cetisli ${ }^{1}$ and Clay J. Naito ${ }^{2}$
}

Received 13 January 2009, accepted 23 May 2009

\begin{abstract}
A study of the axial response of plain concrete under varying confining pressure was conducted to examine the sensitivity of confining pressure on the compressive strength and deformability of concrete. The concrete was examined through the use of a novel triaxial cell with pressure controlled through dilation strain feedback. The study examined realistic levels of constant, linear elastic, elastic-perfectly plastic, and bilinear varying confinement typical of fiber reinforced polymer and steel jacketing applications. It was found that the axial stress-strain response of confined concrete is dependent on the variation of confining pressure applied. The assumption of constant confinement is not appropriate for concrete systems jacketed with passive confinement such as steel or FRP materials. These systems must be comprehensively examined under varying confinement using full-scale jacketed specimens or triaxial studies. The use of a triaxial cell was shown to provide an efficient and cost-effective means of evaluating confinement performance.
\end{abstract}

\section{Introduction}

It has been demonstrated that the axial strength and deformation capacity of concrete increase with the presence of lateral confining pressure. These findings are based on early triaxial testing of concrete cylinders (Richart et al. 1928; Palaniswamy and Shah 1974; Imran and Pantazopoulou 1996; Nielsen 1998; Ansari and Li 1998; Li and Ansari 1999, 2000; Candappa et al. 2001; Sfer et al. 2002; Tan and Sun 2006) which led to the widespread use of lateral reinforcement (Mander et al. 1988a, 1988b; Saatcioglu and Razvi 1992; Razvi and Saatcioglu 1999) and external jackets (Toutanji 1999; Xiao and Wu 2000; Wu et al. 2006) for seismic design and rehabilitation of reinforced concrete columns.

In 1928, Richart et al. conducted a series of constant confinement tests on cylindrical concrete specimens. The levels of confining stress were varied from 5 to 400 percent of the unconfined concrete compressive strength, $f_{c}{ }_{c}$. The results indicated that the increase in strength is directly proportional to the confining pressure applied. The relationship between the confining pressure and the confined strength was presented in the form of MohrCoulomb failure criterion (Eq.1).

$$
f_{c c}=f_{c}^{\prime}+k \times f_{l}
$$

The confined axial strength of the concrete $\left(f_{c c}\right)$ is equated to the confining pressure $\left(f_{1}\right)$ to the unconfined strength of the concrete $\left(f^{\prime}{ }_{c}\right)$. The parameter $k$ was found to be 4.1 based on a least-squares analysis. The parameter, $k$, has been adjusted for transverse rein-

\footnotetext{
${ }^{1}$ Asst. Prof., Dept. of Civil Eng., Firat University, Elazig Turkey.

E-mail:fcetisli@firat.edu.tr

${ }^{2}$ Assoc. Prof., Department of Civil and Environmental Engineering, Lehigh University, PA, USA.
}

forcement (Mander et al. 1988a; Saatcioglu and Razvi 1992; Razvi and Saatcioglu 1999) and fiber reinforced polymer jackets applications (Toutanji 1999; Xiao and Wu 2000; Wu et al. 2006) on both normal and high strength concrete. The values and equations used for $k$ are summarized in a previous study by Naito and Cetisli (2006).

In practical applications, concrete is confined through transverse reinforcement or external jacketing. Confinement becomes active as the concrete dilates. For steel confining materials, the lateral stress can be approximated as constant if it is designed to yield laterally as the concrete crushes. For new confining materials such as carbon and glass fiber reinforced polymers (FRP) or materials with elastic or elastic-hardening constitutive properties, confining stresses continue to increase with dilation of the concrete. For these cases, the assumption of a constant confining pressure is not appropriate.

To account for the variation in confining pressures with dilation, a variable confinement (VC) methodology was developed by Madas and Elnashai (1992) and modified by Kestner et al. (1997) and Harries and Kharel (2002). In this method, the axial deformation is incremented and the level of confining stress is determined based on the amount of dilation present. While this method conceptually incorporates dilation, the constitutive concrete model is based on historical constant confinement experiments.

To develop a comprehensive constitutive model for confined concrete, axial stress-strain data must be generated under varying levels of confinement. Though these effects were examined in previous full-scale confined column studies (Mander et al. 1988b; Saatcioglu and Razvi 1992; Razvi and Saatcioglu 1999), the sensitivity of the concrete axial response is not discernable from the global response of the column. Furthermore, previous triaxial concrete tests (Richart et al. 1928; 
Palaniswamy and Shah 1974; Imran and Pantazopoulou 1996; Nielsen 1998; Ansari and Li 1998; Li and Ansari 1999, 2000; Candappa et al. 2001; Sfer et al. 2002; Tan and Sun 2006) were conducted in a hydrostatic manner where the confining stress was applied initially and kept constant through the axial load history. As a means of examining the sensitivity of axial strength to load path, Imran and Pantazopoulou (1996) varied the confining stress relative to the axial stress. In their study confining stress was initially set to 10 percent of $f^{\prime}{ }_{c}$ and increased 40 percent in a step wise manner with respect to the axial stress. Their results indicated that the axial strength is not sensitive to the path of confinement if it is increased with respect to axial load. Under the loading history applied, however, the confinement was maximized before the concrete crushed. Consequently, the majority of the dilation occurred under a constant confinement condition. This does not realistically represent the variation in confinement that exists in laterally reinforced columns. To simulate the confining pressure variation provided by an external jacketing application a new triaxial test control procedure was developed and is used for the evaluation of normal strength concrete.

\section{Experimental program}

The variable confinement model was developed to provide a realistic approach for modeling dilation and constraint in concrete. When concrete is subjected to axial strain, the system dilates laterally (Fig. 1a). The dilation ratio relationship, $\eta(\varepsilon)$, is initially equal to Poisson's ratio $(0.15)$ and becomes nonlinear as micro-cracking develops in the concrete. Lateral strain of the concrete, $\varepsilon_{l}$, creates an equal axial strain, $\varepsilon_{b}$, in the confining material as a result of compatibility (Fig. 1b). Due to the constitutive properties of the jacket, this strain, $\varepsilon_{l}$, produces a tensile jacket stress, $f_{J}($ Fig. 1c). In accordance with the force equilibrium, this jacket hoop stress creates a confining stress on the dilating concrete, $f_{l}$ (Fig. 1d). Thus the confining pressure acting on an axial loaded concrete element varies as a function of the dilation and the constitutive relationship of the confining material.

As mentioned previously, experimental studies examined concrete confined under a constant-active confining pressure. Conventional jacketing materials such as fiber reinforced polymers (FRP) or steel, however, provide a variation in confinement as the concrete dilates. To properly model the constitutive relationship of the jacket, the confining pressure must be varied relative to the axial strain of the jacket (or lateral strain of the concrete). To model this varying confinement behavior, a triaxial cell mechanism is used to provide an active confining pressure $\left(f_{l}\right)$ in proportion to the lateral strain $\left(\varepsilon_{l}\right)$ measured on cylindrical specimens. The ratio of confining stress to the lateral strain, $E_{c o n}$, can be directly related to the modulus of the jacket material being studied,
$E_{j}$. For circular sections, the relationship between $E_{c o n}$ and the modulus of the jacket is developed based on static equilibrium, compatibility and the constitutive properties and thickness, $t_{j}$, of the jacketing material and the diameter of the concrete, $D$. The relationship is defined in Eq.2. Similar to the $E_{c o n}$, the stiffness of the confinement after the yield level of the fictitious jacket is labeled with $E_{\text {con2 }}$.

$$
E_{\text {con }}=2 \cdot \frac{t_{j}}{D} \cdot E_{j}
$$

\subsection{Confinement demand}

To simulate the varying level of confinement, which is introduced through conventional jacketing or reinforcement, a triaxial cell with dilation feedback was used. Three idealized loading protocols were investigated to mimic the varying confinement typically observed for FRP and steel confining materials. The confining stress was varied in a linearly elastic, elasticperfectly plastic, and a bilinear relationship with respect to the lateral dilation. These protocols were chosen to represent the behavior of jackets made of FRP, steel, and steel with hardening characteristics. In addition, a series of constant confinement tests were conducted to examine the variation between the traditional hydrostatic triaxial tests and the varying confinement response and to provide comparison with previous studies.

A series of confinement stiffness were studied to represent the range of typical jacketing applications. The modulus of the confinement calculated according to Eq.2 was varied from 101 to $2528 \mathrm{MPa}$. These moduli represent a range of jacketing from 1 layer of carbon fiber of thickness $0.10 \mathrm{~mm}$ to $2.8 \mathrm{~mm}$ steel jacket on a $457 \mathrm{~mm}$ diameter column. A summary of the variables studied are presented in Table 1. The volumetric lateral reinforcement ratio (Eq.3) of jacketing/reinforcement material to the concrete, the effective thicknesses, the numbers of jacket layers, on a $457 \mathrm{~mm}$ diameter column

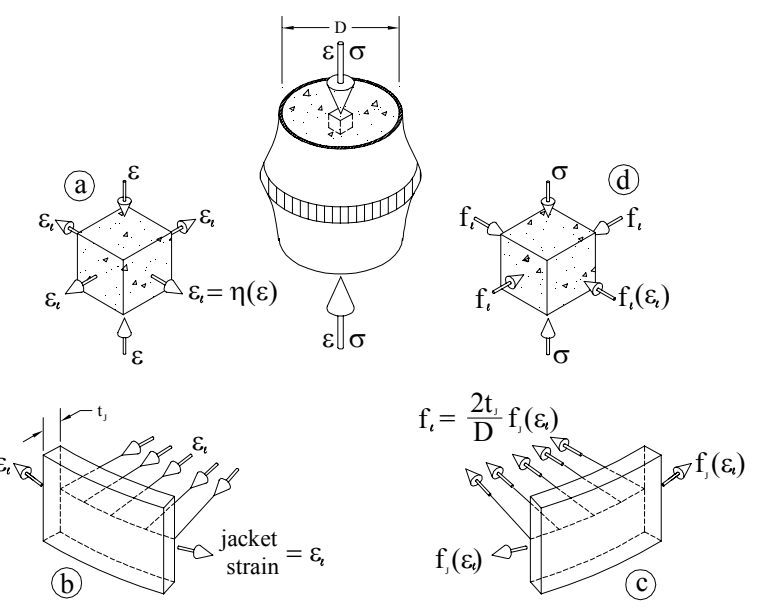

Fig. 1 Confined stress-strain response. 
are presented for each case.

$$
\rho_{j}=\frac{4 \cdot t_{e f f} \cdot\left(D+t_{e f f}\right)}{D^{2}}
$$

\subsubsection{Constant confinement demand}

Three constant confining pressure levels including 4,8 , and 16 percent of $f^{\prime}$, , were examined and these confinement levels were identified as $\mathrm{C} 1, \mathrm{C} 2$, and C3. It was observed from previous studies that practical transverse reinforcement and jacketing are limited to an upper bound of approximately 30 percent of $f_{c}^{\prime}$ (Mander et al. 1988b; Saatcioglu and Razvi 1992; Razvi and Saatcioglu 1999). This level of confinement represents approximately a $4.6 \mathrm{~mm}$ thick steel jacket (Grade 60) on a $457 \mathrm{~mm}$ diameter concrete column with an unconfined strength of $27.6 \mathrm{MPa}$ or a No.4 spiral $(\phi 13 \mathrm{~mm}$, Grade $60)$ at $28 \mathrm{~mm}$ spacing. Exceeding this level of confinement is impractical from a constructability and economic standpoint. Thus, for the constant confinement demand, the confinement range chosen for the research program was varied from 4 to 16 percent of $f^{\prime}{ }_{c}$.

\subsubsection{Elastic-perfectly plastic confinement de- mand}

To model the confinement provided by steel jacketing an idealized elastic-perfectly plastic, EPP, pressure variation was applied. The EPP confining pressure demand was linearly increased until the yield of the fictitious jacket was achieved. The yield level of jacket is taken as a stress of $248 \mathrm{MPa}$ at an axial strain (lateral strain on concrete) of 0.0012 . Following yield of the jacket, the jacket confining stress is held constant until a fracture strain of 0.025 is reached. The EPP series examines three different jacket stiffness levels identified as E1, E2, and E3. To correlate with the constant con- finement series the yield stress was set at 4, 8, and 16 percent of the unconfined compressive strength. This would be physically achieved through an increase in the jacket thickness. The pressure variations used are presented in Fig. 2 and an equivalent effective steel jacket thickness $\left(t_{s}\right)$ for a $457 \mathrm{~mm}$ diameter concrete column is presented in Table 1.

\subsubsection{Linear elastic confinement demand}

To model the confinement provided by FRP jacketing an idealized linear elastic-brittle pressure variation was

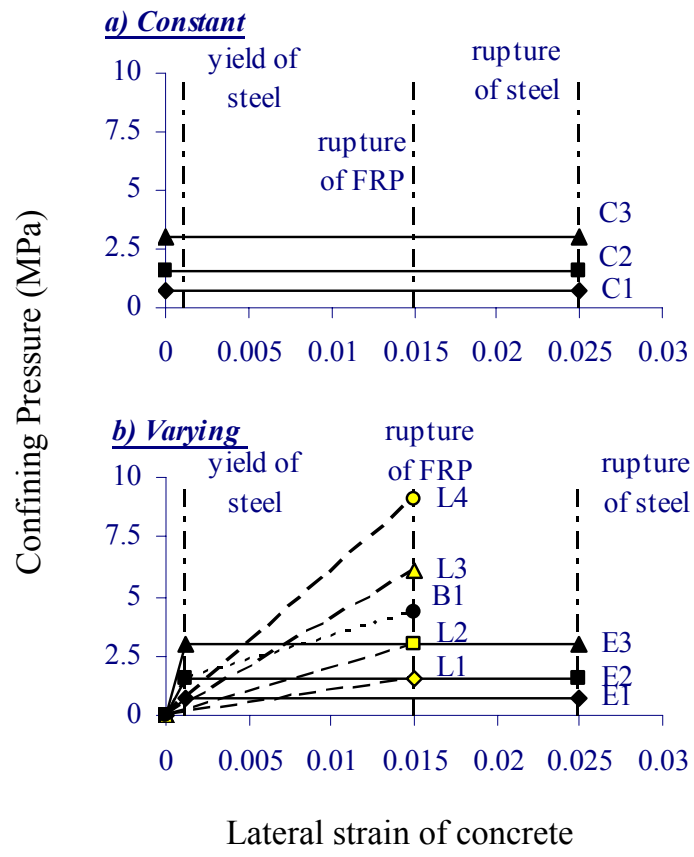

Fig. 2 Confining pressure variations.

Table 1 Test matrix.

\begin{tabular}{|c|c|c|c|c|}
\hline Specimen ID & Max. Applied Pres. (MPa) & $\begin{array}{c}E_{\text {con }}-E_{\text {con2 }} \\
(\mathrm{MPa})\end{array}$ & $\begin{array}{c}\rho_{\mathrm{j}} \\
\left(10^{-3}\right)\end{array}$ & $t_{\mathrm{s}}$ or $n_{\mathrm{j}}$ \\
\hline \multicolumn{5}{|c|}{ Constant Confining Pressure Variation } \\
\hline $\mathrm{C} 1$ & $4 \% f_{\mathrm{c}}^{\prime}-0.76 \mathrm{MPa}$ & $0-0$ & 6.1 & $0.7 \mathrm{~mm}$-steel \\
\hline $\mathrm{C} 2$ & $8 \% f_{c}^{\prime}-1.52 \mathrm{MPa}$ & $0-0$ & 12.3 & $1.4 \mathrm{~mm}$-steel \\
\hline C3 & $16 \% f_{\mathrm{c}}^{\prime}-3.04 \mathrm{MPa}$ & $0-0$ & 24.6 & $2.8 \mathrm{~mm}$-steel \\
\hline \multicolumn{5}{|c|}{ Elastic-perfectly Plastic Confining Pressure Variation } \\
\hline E1 & $4 \% f_{\mathrm{c}}^{\prime}-0.76 \mathrm{MPa}$ & $606-0$ & 6.1 & $0.7 \mathrm{~mm}$-steel \\
\hline E2 & $8 \% f_{\mathrm{c}}^{\prime}-1.52 \mathrm{MPa}$ & $1264-0$ & 12.3 & $1.4 \mathrm{~mm}$-steel \\
\hline E3 & $16 \% f_{\mathrm{c}}^{\prime}-3.04 \mathrm{MPa}$ & $2528-0$ & 24.6 & $2.8 \mathrm{~mm}$-steel \\
\hline \multicolumn{5}{|c|}{ Linear Confining Pressure Variation } \\
\hline L1 & $8 \% f_{c}^{\prime}-1.52 \mathrm{MPa}$ & $101-101$ & 0.9 & 1 layers-CFRP \\
\hline L2 & $16 \% f_{\mathrm{c}}^{\prime}-3.04 \mathrm{MPa}$ & $202-202$ & 1.8 & 2 layers-CFRP \\
\hline L3 & $32 \% f_{\mathrm{c}}^{\prime}-6.08 \mathrm{MPa}$ & 404-404 & 3.6 & 4 layers-CFRP \\
\hline L4 & $48 \% f_{\mathrm{c}}^{\prime}-9.10 \mathrm{MPa}$ & $606-606$ & 5.4 & 6 layers-CFRP \\
\hline \multicolumn{5}{|c|}{ Bilinear Confining Pressure Variation } \\
\hline \multirow[t]{2}{*}{ B1 } & \multirow[t]{2}{*}{$8 \% f_{\mathrm{c}}^{\prime}-1.52 \mathrm{MPa}$} & \multirow{2}{*}{$\begin{array}{c}1264- \\
202\end{array}$} & 10.3 & $1.2 \mathrm{~mm}$-steel \\
\hline & & & 1.8 & 2 layers-CFRP \\
\hline \multicolumn{5}{|c|}{ Unconfined } \\
\hline
\end{tabular}


applied. Four levels of confinement stiffness, computed in accordance with Eq.2, were investigated L1, L2, L3, and L4 (Fig. 2. The confinement levels simulate 1 to 6 layers of a conventional carbon fiber reinforced polymer (CFRP) jacket application on a $457 \mathrm{~mm}$ diameter column (Table 1). The material characteristics of the CFRP sheets are defined with the thickness of $0.1 \mathrm{~mm}$, an elastic modulus of $2.28 \times 10^{5} \mathrm{MPa}$, and an axial strain at rupture of 0.015 .

\subsubsection{Bilinear confinement demand}

To simulate a jacketed reinforced concrete column or confining material that has a hardening behavior, a bilinear confining pressure demand was used. The initial confinement stiffness correlates with series E2. Following yield, which occurs at a lateral strain of 0.0012 , the stiffness is reduced to 16 percent of the elastic stiffness (Fig. 2). One test series, B1, was examined under this condition. This confining level is equivalent to 1 percent ratio of lateral steel reinforcement in combination with two layers of CFRP (Table 1).

\subsection{Material properties}

To simulate the typical retrofit applications a conventional normal weight concrete of average strength was used. The concrete mixture was designed to reach the compressive strength of $24.1 \mathrm{MPa}$ at 28 days. At an age of 28 days, the compressive and the splitting tension strengths were measured in accordance with American Society for Testing and Material (ASTM) standards C39 (2001) and C496 (1996). The compressive strength was $25.9 \mathrm{MPa}$ and the splitting tension strength $2.84 \mathrm{MPa}$, respectively, for average of three tests. The static modulus of the concrete was recorded as $32940 \mathrm{MPa}$ (ASTM, 1994). The mix design that was used utilizing with \#8 aggregate is presented in Table 2.

To provide a realistic distribution of aggregate, specimens were obtained through core drilling of concrete blocks, which were in dimensions of $1524 \times 1524 \times 330 \mathrm{~mm}$ and cured by covering wet burlaps for 7-days, at an age of 7-days and cured in a curingtank at laboratory conditions according to ASTM C19200 (2000) requirements after being drilled. To ensure flat and perpendicular end conditions and in order to minimize the friction in between the specimen and the platens to the testing mechanism, the both ends of cylinders were saw-cut prior to testing. The specimens had a height of $305 \mathrm{~mm}$ and a diameter of $102 \mathrm{~mm}$. The aspect ratio of three was chosen to provide uniform stress distributions in the instrumented section. This ratio is larger than the typical value of two used for conventional compression testing of concrete. Research by Theriault et al. (2004) has shown that the variation in aspect ratio from 2 to 3 has no effect on confined concrete response. The measured response of unconfined concrete specimens is presented in Fig. 3 with a comparison of the stress-strain distribution model of Popovics (1973).
Table 2 Concrete proportions.

\begin{tabular}{|l|c|c|}
\hline Material Type & Units & Batch \\
\hline Total Cement & $\mathrm{kg} / \mathrm{m}^{3}$ & 262 \\
\hline Slag Cement & $\mathrm{kg} / \mathrm{m}^{3}$ & 136 \\
\hline Fine Aggregate & $\mathrm{kg} / \mathrm{m}^{3}$ & 1044 \\
\hline Coarse Aggregate [\#67] & $\mathrm{kg} / \mathrm{m}^{3}$ & 0 \\
\hline Coarse Aggregate [\#8] & $\mathrm{kg} / \mathrm{m}^{3}$ & 1044 \\
\hline Water/Cement Ratio & & 0.51 \\
\hline Water Reducer (DCEM-55) & $1 \mathrm{t} / \mathrm{m}^{3}$ & 0.56 \\
\hline Target Air Content & $\%$ & $\mathrm{NA}$ \\
\hline Target Slump & $\mathrm{mm}$ & 102 \\
\hline Compressive Strength - 28 $8^{\text {th }}$ day & $\mathrm{MPa}$ & 26 \\
\hline Splitting Tension Strength & $\mathrm{MPa}$ & 2.84 \\
\hline St. Deviation (Comp. Strength) & $\mathrm{MPa}$ & 0.22 \\
\hline
\end{tabular}

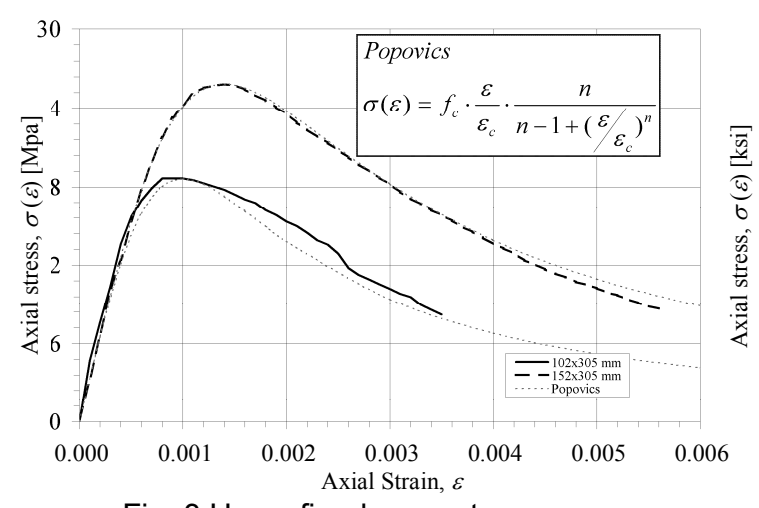

Fig. 3 Unconfined concrete response.

\section{Testing procedure}

To examine the variation of confinement with dilation a triaxial cell and universal testing machine was used (Fig. 4). The triaxial cell is capable of testing rock or concrete specimens with a diameter of $102 \mathrm{~mm}$ and a height of 254 to $305 \mathrm{~mm}$ at confining pressures of up to $69.5 \mathrm{MPa}$. The system consists of a hydraulic power supply, a pressure intensifier, an analog controller, data acquisition system with axial and lateral deformation measurement devices, and the cell itself. The resolution of the system allowed for a $68.95 \mathrm{kPa}$ increment in confining pressure.

The testing procedure consisted of a series of deformation steps: 1) axial deformation was applied to the cylinder through a universal test machine, 2) lateral deformation was measured at mid height, 3) confining pressure was increased with respect to the lateral dilation through the triaxial cell, based on the linear, EPP, or bilinear relationship examined, and 4) steps 1 through 3 were repeated until a significant loss in strength occurred (Fig. 4). The tests were continued until the failure criterion was reached. The failure criterion is defined with the significant loss in the strength or the ultimate lateral deformation, which was an equivalent of 0.015 for test series-L and 0.025 for test series-C, E, and $\mathrm{B}$. 
The deformations in longitudinal and lateral directions are measured on concrete specimens (Fig. 4) inside the triaxial cell testing mechanism. Since the offset failure mode (Fig. 5c) causes inaccurate measurements of the deformations, the data is decided to be neglected or not depending on the failure mode observed for each test.

\section{Experimental results}

The failure modes of the tested specimens and the confined concrete test results are presented in Fig. 5 and

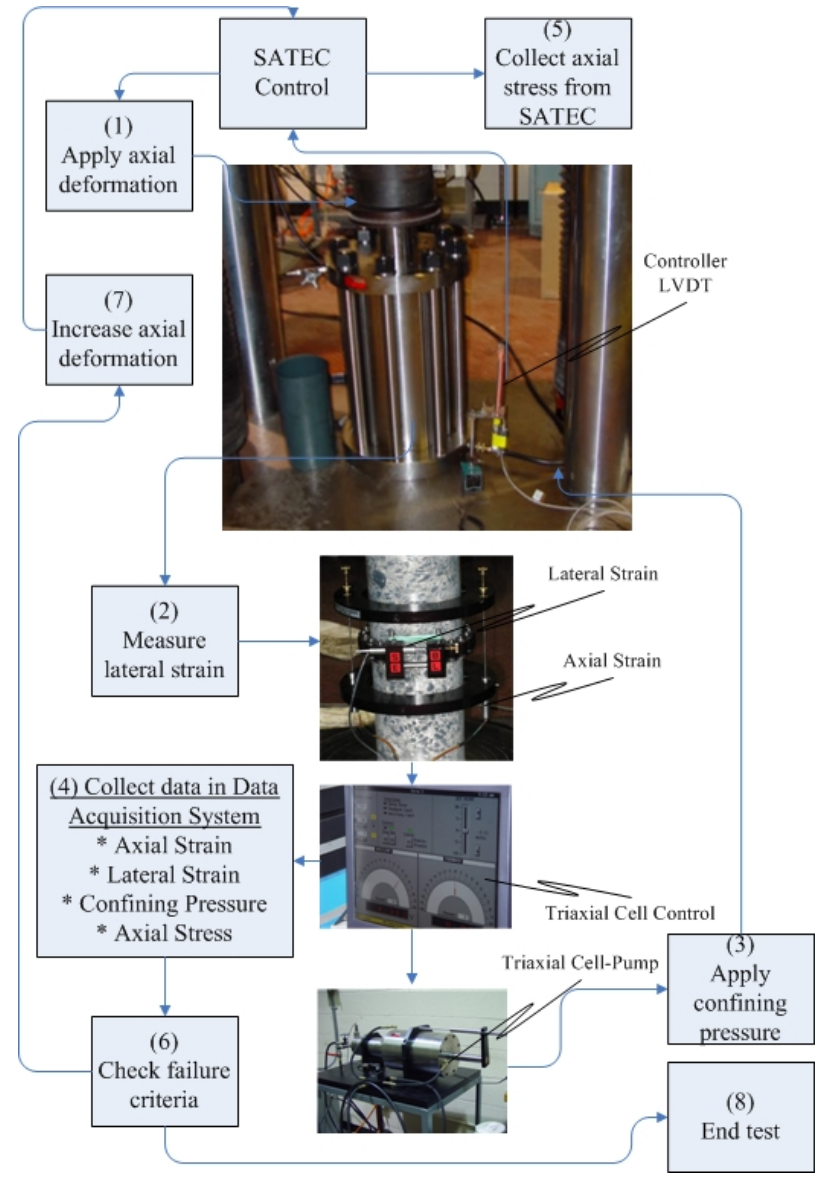

Fig. 4 Control procedure and test setup.
Fig. 6, respectively. The measured axial stress - strain response is presented along with the applied confining pressure axial strain response in Fig. 6a, b, and c. The confining pressure response is denoted with a " $p$ " to differentiate it from the axial data. The dilation ratio (the ratio of lateral strain to axial strain) is presented with respect to axial strain in Fig. 6d, e, and f. The constant test series (C) is presented in Fig. 6a and d, the EPP series (E) is presented in Fig. $6 \mathbf{b}$ and e, and the linear series (L) is presented in Fig. 6c and f. For each test series, the responses of two specimens are presented in Fig. 6 (i.e. C301 and C302 are the results for C3 test series). The results illustrate the sensitivity of axial response (Fig. 7) and dilation to the variation of confining pressure. A detailed discussion of the characteristics of each group and a comparison between the confinement groups is as following.

\subsection{Constant confinement response}

In the constant confinement test series, increasing confinement resulted in the expected increase in ultimate (peak) compressive strength and corresponding axial strain. The axial stress strain and corresponding confining stress are averaged and presented in Fig. 8. The resistance decreased with increasing axial strain after the ultimate strength was reached. The severity of the strength decrease was greater for low levels of confinement.

The constant confinement test results compared well with the data of Richart et al. (1928). A linear regression of the peak compressive strengths measured in this study resulted in a $k$ value of $4.85\left(\mathrm{R}^{2}=0.77\right)$. While this value is much higher than the 4.1 value widely used, a regression of a portion of the data of Richart et al. up to 20 percent $f^{\prime}{ }_{c}$ results in the same $k$ of $4.85\left(\mathrm{R}^{2}=0.99\right)$. The peak compressive strengths measured for the various confinement levels are compared with the data of Richart et al. in Fig. 9.

The dilation ratio (ratio of the lateral circumferential- strain to the axial strain) behavior of the concrete is defined with providing a positive sign convention for the expansion in lateral dimensions under axial compression of the concrete. The dilation ratio of concrete under constant confining pressure test series

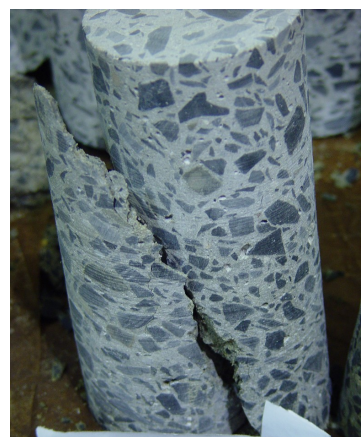

(a) shear

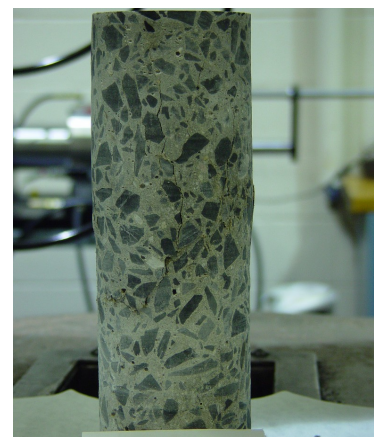

(b) cone

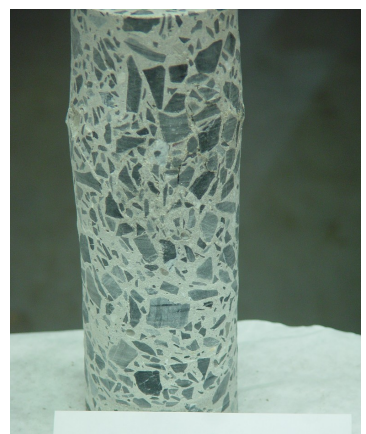

(c) offset failure

Fig. 5 Cylinder failure modes. 

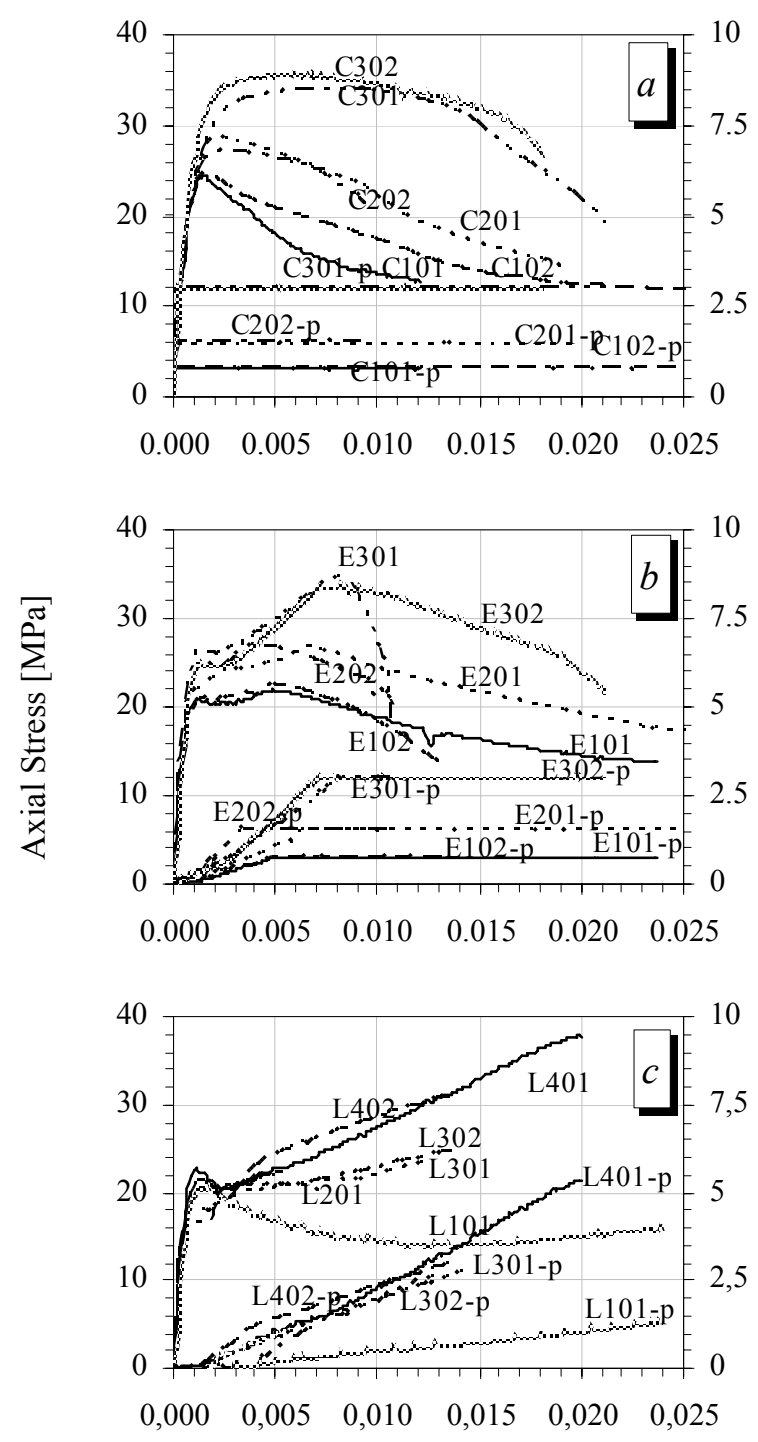

Axial Strain
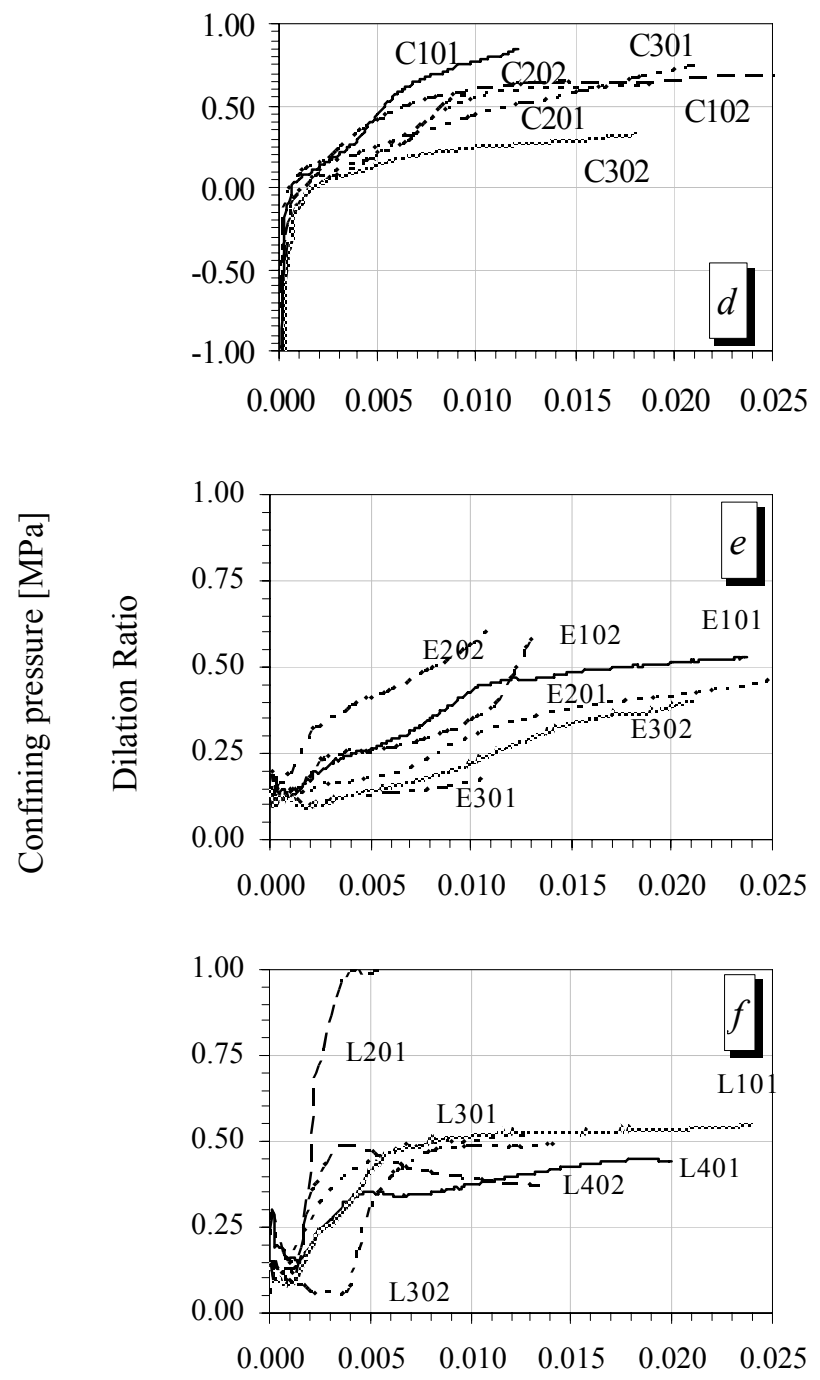

Axial Strain

Fig. 6 Cumulative test results.

started from a value of approximately -1.0 due to the initial hydrostatic compression loading (Fig. 6d). Upon application of the axial deformation the dilation ratio increased. Herein a model by Oh and Sause (2006) proposed a value of 0.4 for the dilation ratio at the peak compressive strength, however, this trend was not observed.

\subsection{Elastic-perfectly plastic confinement re- sponse}

In the elastic-perfectly plastic confining pressure variation test series, the confining pressure was increased from zero to the yield of the virtual steel jacket and kept constant. The strength reached a maximum at the onset of yielding (lateral strain of 0.0012 for concrete) and decreased after the confining pressure became constant (Fig. 10). All specimens failed in axial compression prior to achieving the ultimate strain in the virtual jacket.

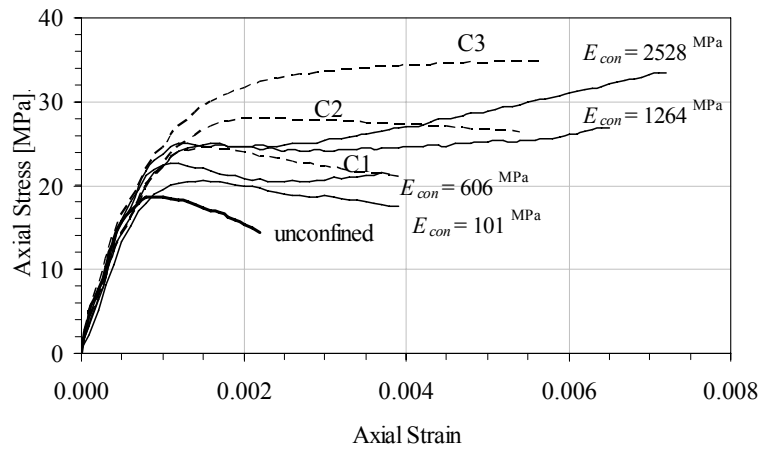

Fig. 7 Sensitivity of confining stiffness and pressure on axial response.

The initial dilation ratio of the concrete is equal on the average to a dilation ratio of 0.14 . Once the con- 
crete exceeds the elastic limit the dilation increases with increasing axial strain (Fig. 11). In general, as the confining stress becomes constant, change in trend of the dilation ratio with respect to the axial strain is observed. After this point, the generalized trend of the dilation ratio behavior is to reach and asymptote with a decreasing rate. However, at low confinement levels (i.e. test series-E1) abrupt failures, which affect the deformation measurements, and differentiation from the generalized trend can be observed.

\subsection{Linear confinement response}

The axial stress-strain responses of the four linear confinement series are presented in Fig. 12. The cylinders exhibited varied in the initial compression strength. Lin-

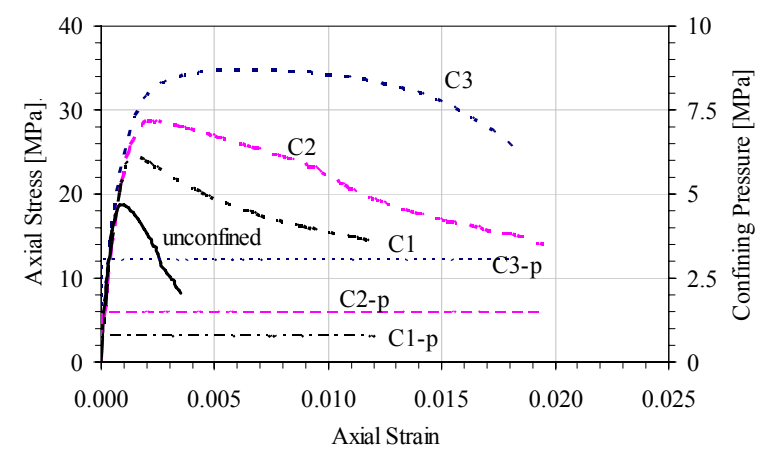

Fig. 8 Constant confinement stress-strain response.

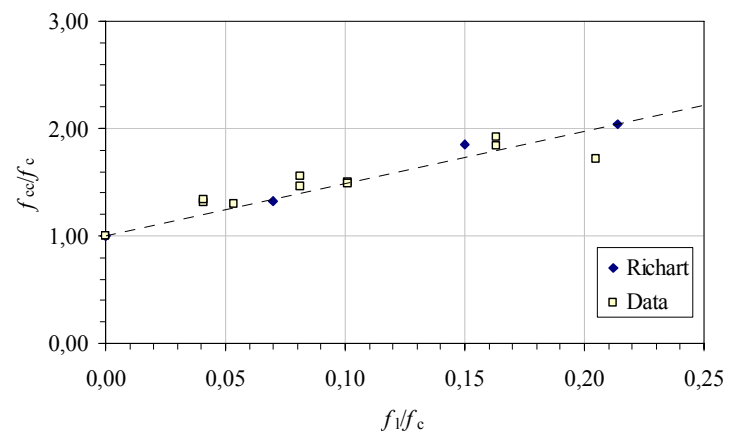

Fig. 9 Peak compressive strength for constant confinement.

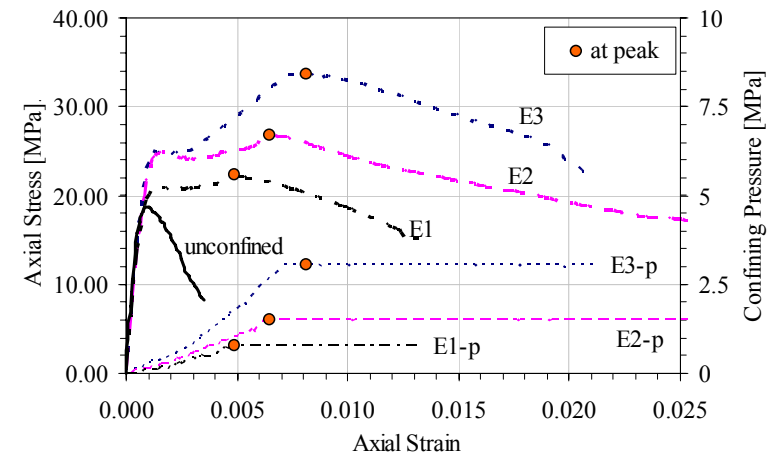

Fig. 10 EPP stress-strain response. ear increase in confining pressure results in an increase in axial strength and axial deformation capacity. However, the axial deformation capacity of L1 series exceeded capacity of L2 and L3 series and reached same capacity as of L4 series. As the stiffness of the confinement increases the post peak axial stress-strain changes from a softening to hardening response. As a consequence, the failure modes were not consistent between specimens and the ultimate strains should not be used as a research finding.

It is observed with the linear confinement test series that Linear Confinement test series provide low confinement stiffness (for the same confinement level) when compared to Elastic-Perfectly Plastic Confinement test series. Since the confinement stiffness is considerably low (i.e. L1 and L2 test series), it wasn't possible to apply a confining pressure at unconfined compressive strength level. Before the unconfined strength reached, concrete exhibit elastic behavior which results in a dilation ratio that is equivalent to Poisson's ratio (approximately 0.14). As the unconfined strength is reached, micro-cracking occurs and the lateral dilation of the concrete increases rapidly. After this point, it is possible to apply a confining pressure (Fig. 6c). As the confining pressure is applied on the specimen, changes in the trend of both the axial stress-strain response and the dilation ratio behavior (Fig. 13) are observed. Similar to Elastic-Perfectly Plastic confinement test series, the dilation ratio behavior reaches to an asymptote, which decreases with the level of confinement stiffness.

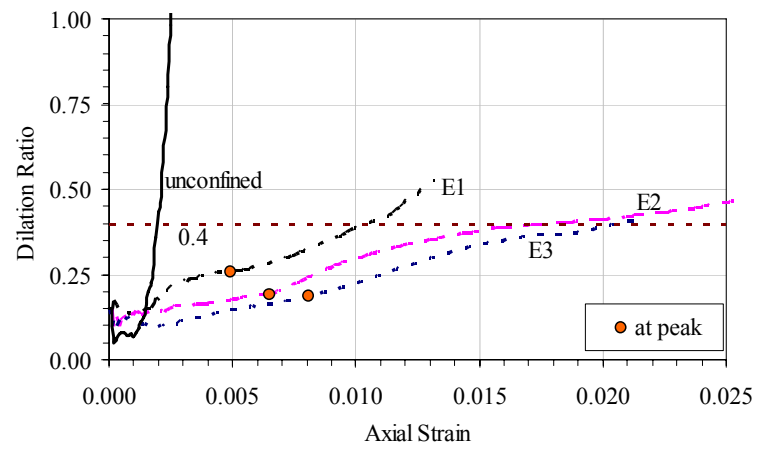

Fig. 11 EPP dilation ratio response.

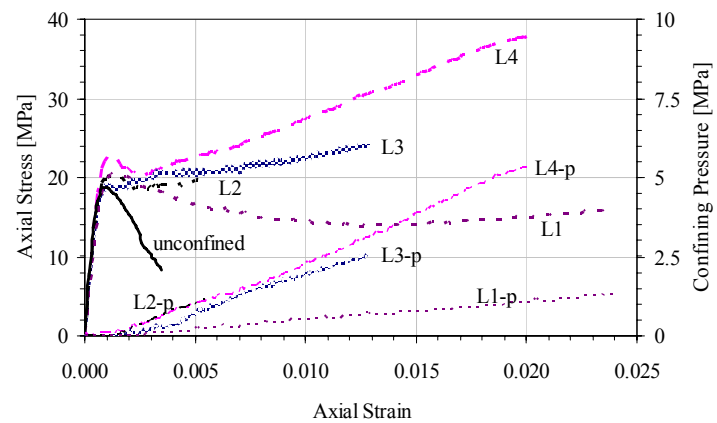

Fig. 12 Linear confinement stress-strain response. 
The exception to this observation is the linear case L2 where the dilation increases. This can be attributed to an abrupt failure observed on the specimen and is notable on the axial stress-strain response.

\subsection{Bilinear confinement response}

A bilinear variation in confinement was applied to a concrete cylinder. The confinement consisted of an initial stiffness equal to EPP case E2, $1263 \mathrm{MPa}$, and a secondary stiffness equal to 16 percent of the initial. The axial stress-strain and the applied confinement are compared with E2 in (Fig. 14). As shown previously in Fig. 10, the axial strength of confined concrete decreases after confining pressure becomes constant. The results indicate that the application of a secondary stiffness prevents a loss in strength. The difference in response between the EPP and bilinear response can be attributed to the continued active confinement applied.

\subsection{Comparison of test series}

A comparison of the constant, linear and elasticperfectly plastic confinement histories was conducted to examine the sensitivity of the axial strength to the path of applied confinement. In Fig. 15, the axial stressstrain and lateral confinement of cylinders with intersecting levels of applied confinement are compared. Five test series are compared in two separate plots Fig. 15a and $\mathbf{b}$. The point at which the same confining pressure - axial strain response intersect is noted with a solid square. In general, the axial strengths of the concretes

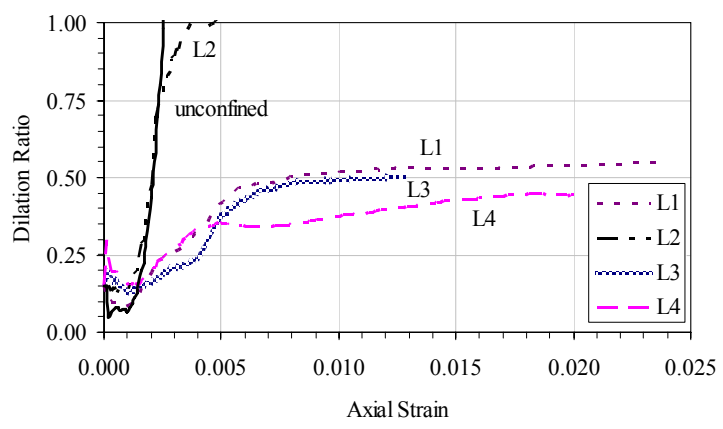

Fig. 13 Linear confinement dilation ratio response。

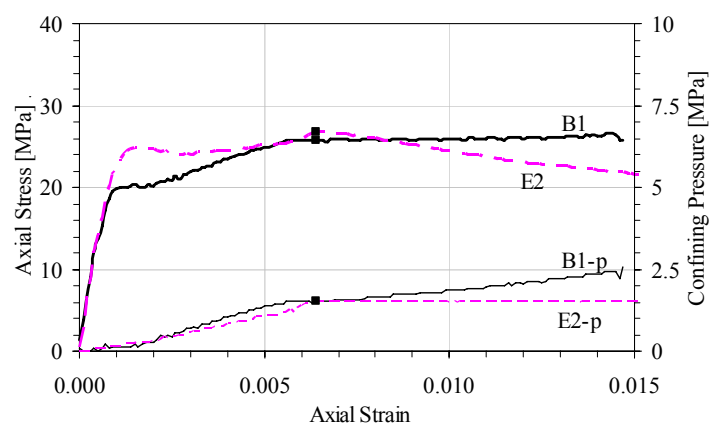

Fig. 14 Stress-strain response comparison of E2 and B1. are equal when the same confining pressure is applied at a given axial strain. This indicates that the axial strength is independent of the path under which the confinement is applied.

For the series where the confining pressure - axial strain history coincide, the axial stress-strain response are comparable. In Fig. 16a, the same initial confining stress - axial strain history produces the same initial axial response. Once the confinement varies the axial response no longer matches. If the confinement matches later in the load history the same trend is observed. Figure 16b illustrates that when the EPP and constant confinement histories meet, the unloading of the axial stress-strain is on the same order.

The variation of dilation ratio with axial strain for the different test series are compared in Fig. 17. The presence of confining pressure produces a decrease in the magnitude of the dilation. This is illustrated by comparing the unconfined data with the constant, linear and EPP. The level of dilation is also dependent on the initial stiffness under which the confinement is applied. For higher initial confinement stiffness the dilation history is lower as illustrated in a comparison of E3, E2, and L4. This may be attributed to the possibility that as the confinement stiffness increases the concrete is prevented from dilating earlier in its history which limits initial crushing and overall dilation.

\section{Conclusions and recommendations}

The research developed a method for the application of variable lateral confinement to concrete cylinders under

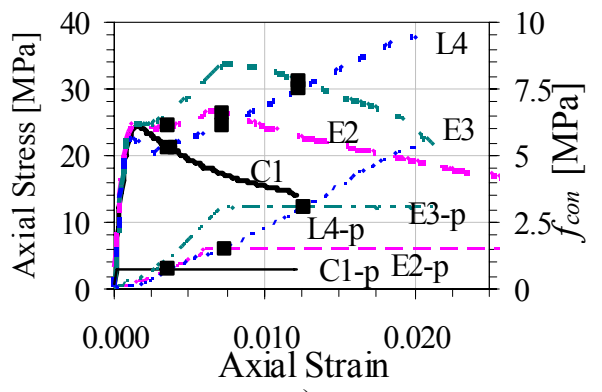

a)

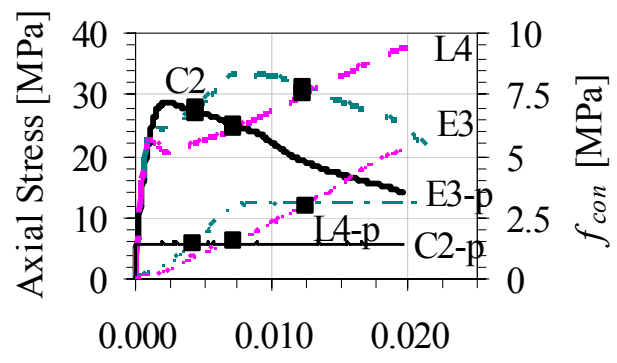

Axial Strain

b)

Fig. 15 Confinement path independence on compressive strength. 


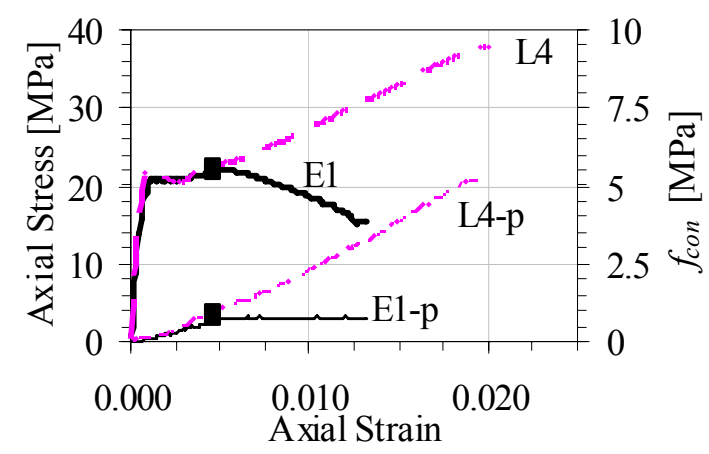

a)

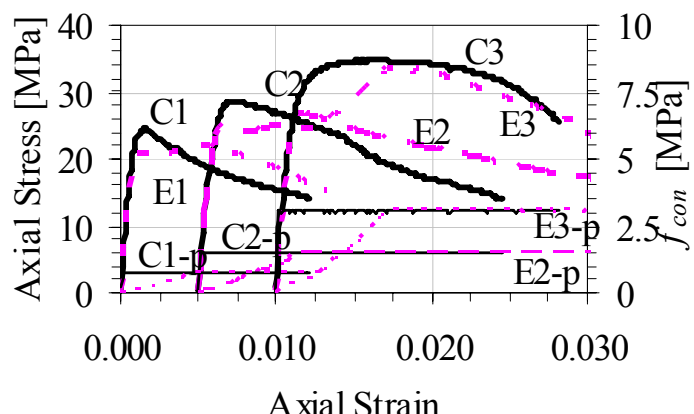

Axial Strain

b)

Fig. 16 Confinement path dependence on axial stressstrain response.

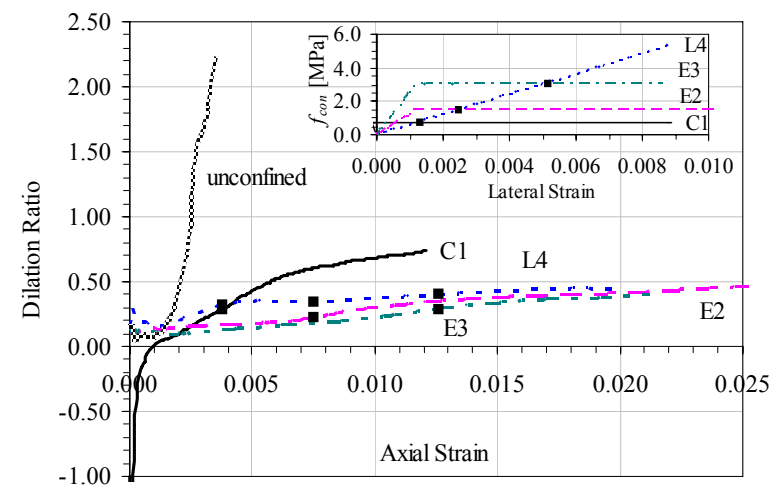

Fig. 17 Comparative dilation ratio responses.

axial demand. Based on the presented results and discussion, the following conclusions are made:

- The effect of variable confinement corresponding to the linear elastic, elastic-perfectly plastic, and bilinear jacketing materials can be modeled using a triaxial cell testing mechanism with feedback control of the lateral strain. This system can be extended to provide efficient studies on the effect of various jacketing material properties on concrete's axial strength and deformability.

- The strength of concrete with constant confinement correlates with the data available in the literature.
The constant of Mohr-Coulomb failure criteria, $k$, is equal to 4.85 for confinement levels typical of jacketing applications (less than 20 percent of $f^{\prime}$ ). This value is higher than the typical value of 4.1 used.

- A comparison of axial stress-strain of concrete under constant confinement and concrete under elasticperfectly plastic (EPP) confinement was made. For the same peak confining pressure, the varying confinement history produced a decrease in the ultimate axial strength with an increase in the corresponding axial strain. This indicates that the assumption of constant confinement for jacketed systems with elastic-perfectly plastic material properties may be unconservative.

- A discontinuity in the confining pressure history results in a change in the axial response. A change from a linear elastic confinement to a plastic results in a decrease in the axial strength. This indicates that the loss of active confinement results in a loss in strength.

- Increase in confinement stiffness produces an increase in the axial stiffness after the unconfined strain is exceeded. The choice of the confining stiffness can alter the axial stiffness from a softening to hardening behavior.

- In general, the axial strengths of the concretes are equal when the same confining pressure is applied at a given axial strain. This indicates that the axial strength is independent of the path under which the confinement is applied.

- Coinciding confining stress - axial strain history produces the same axial response.

- The dilation for confined concrete follows a tri-linear trend. For higher initial confinement stiffness the dilation history is lower.

The research has shown that the axial stress-strain history of confined concrete is dependent on the variation of confining pressure applied. The assumption of constant confinement is not appropriate for concrete systems jacketed with passive confinement such as steel or FRP materials. Hence it is observed that the modulus of confinement and the discontinuities in the confinement demand affect the confined concrete behavior, it is found with this study that the constant confinement may not be appropriate for passively confined concrete systems (such as FRP and steel jacketing). So that, the common characteristics of concrete confined by different jacketing mechanisms needs to be well defined. These systems must be comprehensively examined under varying confinement using full-scale jacketed specimens or triaxial studies. The testing of small triaxial specimens provides an efficient and cost-effective means of evaluating confinement performance. 


\section{Acknowledgements}

The research was financed in part by the Pennsylvania Department of Transportation and a grant from the Commonwealth of Pennsylvania, the Department of Community and Economic Development, through the Pennsylvania Infrastructure Technology Alliance (PITA). The authors would also like to thank the Republic of Turkey, the Ministry of National Education for the graduate student support.

\section{List of notations}

$D$ Diameter of the concrete column

$\varepsilon \quad$ Axial strain of concrete

$\varepsilon_{c} \quad$ Axial strain corresponding to peak unconfined compressive strength of concrete

$\varepsilon_{c c} \quad$ Axial strain corresponding to peak confined compressive strength of concrete

$\varepsilon_{l} \quad$ Transversal (lateral) strain of concrete

$\varepsilon_{f r} \quad$ Rupture strain of FRP jacket or steel tube

$\varepsilon_{y} \quad$ Yield strain of steel jacket

$E_{c} \quad$ Elastic modulus of the unconfined concrete

$E_{c o n}$ Elastic modulus (initial stiffness before the yield level, $\varepsilon_{1}=0.0012$ ) of the confining pressure

$E_{\text {con } 2}$ Elastic modulus of the confining pressure after the yield level $\left(\varepsilon_{\mathrm{l}}=0.0012\right)$

$E_{j} \quad$ Elastic modulus of the FRP jacket $\left(E_{\mathrm{f}}\right)$ or steel tube $\left(E_{\mathrm{s}}\right)$

$f(\varepsilon)$ Stress distribution with respect to the axial strain

$f_{c} \quad$ Peak unconfined compressive strength of concrete

$f_{c c} \quad$ Peak confined compressive strength of concrete

$f_{j} \quad$ Stress in the FRP jacket or steel tube

$f_{l} \quad$ Lateral confining pressure

$f_{f r} \quad$ Rupture strength of FRP jacket or steel tube

$f_{y} \quad$ Yield strength of steel tube

$k \quad$ The effect of confining pressure to the peak confined strength of concrete

$k_{2} \quad$ Coefficient affecting curvature of descending branch of stress-strain curve

$k_{2}=0.58+16\left(f_{l} / f_{c 0}\right)^{1.4}$

$k_{3} \quad$ Coefficient to reflect the effect of concrete strength $k_{3}=\left(40 / f_{c 0}\right) \leq 1.0$

$n \quad$ Modular ratio $n=E_{c} \cdot\left[E_{c}-\left(f_{c} / \varepsilon_{c}\right)\right]^{-1}$

$n_{j} \quad$ Number of layers of the FRP jacket

$\eta(\varepsilon)$ Dilation ratio relationship defined with respect to the axial strain of concrete

$\eta_{u} \quad$ Ultimate value for the dilation ratio of the concrete

$v_{p} \quad$ Initial value for the dilation ratio of the concretePoisson's ratio

$\rho_{j} \quad$ Volumetric ratio of the FRP or steel to concrete

$t_{\text {eff }}$ Effective thickness of the FRP jacket $\left(n_{\mathrm{j}} \times t_{\mathrm{f}}\right)$ or steel tube $\left(t_{\mathrm{s}}\right)$

$t_{f} \quad$ Thickness of the one layer FRP jacket

$t_{s} \quad$ Thickness steel tube or the equivalent thickness of the transverse steel reinforcement

\section{References}

Ansari, F. and Li, Q. (1998). "High strength concrete subjected to triaxial compression." Materials Journal-ACI, 95(6), 744-755.

ASTM, (2001). "Standard test method for compressive strength of cylindrical concrete specimens: Designation C39-01." Philadelphia, Pennsylvania: American Society for Testing Materials.

ASTM, (1996). "Standard test method for static splitting tensile strength of cylindrical concrete specimens: Designation C469-96." Philadelphia, Pennsylvania: American Society for Testing Materials.

ASTM, (1994). "Standard test method for static modulus of elasticity and Poisson's Ratio of concrete in compression: Designation C469-94." Philadelphia, Pennsylvania: American Society for Testing Materials.

ASTM, (2000). "Standard Practices for Making and Curing Concrete Test Specimens in the Laboratory: Designation C192-00." Philadelphia, Pennsylvania: American Society for Testing Materials.

Candappa, D. C., Sanjayan, J. G. and Setunge, S. (2001). "Complete triaxial stress-strain curves of highstrength concrete." The Journal of Materials in Civil Engineering-ASCE, 13(3), 209-215.

Elwi, A. A. and Murray, D. W. (1979). "A 3D hypoelastic concrete constitutive relationship." The Journal of Engineering Mechanics-ASCE, 105(4), 623-641.

Harries, K. A. and Kharel, G. (2002). "Behavior and modeling of concrete subject to variable confining pressure." Materials Journal-ACI, 99(2), 180-189.

Imran, I. and Pantazopoulou, S. J. (1996). "Experimental study of plain concrete under triaxial stress.” Materials Journal-ACI, 93(6), 589-601.

Kestner, J. T., Harries, K. A., Pessiki, S. P., Sause, R. and Ricles, J. M. (1997). "Rehabilitation of reinforced concrete columns using fiber reinforced polymer composite jackets." Bethlehem, PA, USA: Lehigh University ATLSS Engineering Research Center, Report No.97-07.

Légeron, F. and Paultre, P. (2003). "Uniaxial confinement model for normal- and high-strength concrete columns." The Journal of Structural Engineering-ASCE, 129(2), 241-252.

Li, Q. and Ansari, F. (1999). "Mechanics of damage and constitutive relationships for high strength concrete in triaxial compression." The Journal of Engineering Mechanics-ASCE, 125(1), 1-10.

Li, Q. and Ansari, F. (2000). "High strength concrete in triaxial compression by different sizes of specimens." Materials Journal-ACI, 97(6), 684-689.

Madas, P. and Elnashai, A. S. (1992). "A new passive confinement model for the analysis of concrete structures subjected to cyclic and transient dynamic loading." Earthquake Engineering and Structural Dynamics-John Wiley and Sons, Ltd., 21, 409-431.

Mander, J. B., Priestly, M. J. N. and Park, R. (1988a). "Theoretical stress-strain model for confined 
concrete." The Journal of Structural EngineeringASCE, 114(8), 1804-1826.

Mander, J. B., Priestly, M. J. N. and Park, R. (1988b). "Observed stress-strain behavior of confined concrete." The Journal of Structural EngineeringASCE, 114(8), 1827-1849.

Naito, C. J. and Cetisli, F. (2006). "Accuracy and improvements for variable and constant confinement concrete models." In: SP-238: International Symposium on Confined Concrete. MI, USA: ACI, 238, 157-176.

Nielsen, C. V. (1998). "Triaxial behavior of highstrength concrete and mortar." Materials Journal$A C I$, 95(2), 144-151.

Oh, B. and Sause, R. (2006). "Empirical models for confined concrete under uniaxial loading." In: SP238: International Symposium on Confined Concrete. MI, USA: ACI, 238, 141-156.

Palaniswany, R. and Shah, S. P. (1974). "Fracture and stress-strain relationship of concrete under triaxial compression." The Journal of the Structural Division-ASCE, 100(ST5), 901-916.

Popovics, S. (1973). "A numerical approach to the complete stress-strain curve of the concrete." Cement and Concrete Research, 3(4), 583-589.

Razvi, S. R. and Saatcioglu, M. (1999). "Confinement model for high-strength concrete." The Journal of Structural Engineering-ASCE, 125(3), 281-289.

Richart, F. E., Brandtzaeg, A. and Brown, R. L. (1928). "A study of the failure of concrete under combined compressive stresses." Illinois, USA: Engineering Experiment Station at University of Illinois, Bulletin No. 185.
Saatcioglu, M. and Razvi, S. R. (1992). "Strength and ductility of confined concrete." The Journal of Structural Engineering-ASCE, 118(6), 1590-1607.

Sfer, D., Carol, I., Gettu, R. and Etse, G. (2002). "Study of the behavior of concrete under triaxial compression." The Journal of Engineering Mechanics-ASCE, 128(2), 156-163.

Tan, T.-H. and Sun, X. (2006). "Failure criteria of concrete under triaxial compression." In: SP-238: International Symposium on Confined Concrete. MI, USA: ACI, 238, 235-248.

Theriault, M., Neale, K. W. and Claude, S. (2004). "Fiber-reinforced polymer confined circular concrete columns." The Journal of Composites for Construction-ASCE, 8(4), 323-331.

Toutanji, H. A. (1999). "Stress-strain characteristics of concrete columns externally confined with advanced fiber composite sheets." Materials Journal-ACI, 96(3), 397-405.

Watanabe, F. (1972). "Mechanical behavior of materials." Proceedings of the International conference on mechanical behavior of materials, The society of material science, Japan, 4, 153-161.

Wu, G., Wu, Z. S., Lu, Z. T. and Ando, Y. B. (2006). "Experimental study on concrete cylinders confined with various FRP under uniaxial compression." In: SP-238: International Symposium on Confined Concrete. MI, USA: ACI, 238, 381-394.

Xiao, Y. and Wu, H. (2000). "Compressive behavior of concrete confined by carbon fiber composite jackets." The Journal of Materials in Civil Engineering-ASCE, 12(2), 139-146. 